\title{
Optimization of Stakeholder Relation Network of the Qingdao Elderly Livable Community Construction Project
}

\author{
Mingyuan Dong (iD) and Guolei Liu (iD \\ School of Public Administration, Central China Normal University, Wuhan 430079, China \\ Correspondence should be addressed to Guolei Liu; lgl_1022@126.com
}

Received 17 September 2020; Revised 14 October 2020; Accepted 28 October 2020; Published 16 November 2020

Academic Editor: Guangdong Wu

Copyright (c) 2020 Mingyuan Dong and Guolei Liu. This is an open access article distributed under the Creative Commons Attribution License, which permits unrestricted use, distribution, and reproduction in any medium, provided the original work is properly cited.

\begin{abstract}
Due to the population ageing, building an elderly livable community has become an urgent task of social welfare development. This Public-Private Partnership construction project faces a variety of pressures from its complex stakeholders. Based on the Qingdao elderly livable community construction project, this paper builds up interpretations about its relationship governance by conducting stakeholder analysis. The paper aims to explore the relationship governance mechanism of multiple connections between related stakeholders. On the basis of complex network theory, this paper establishes a stakeholder relationship network model and describes different modes of different stakeholder relationship in the Qingdao construction project. The paper analyzes the optimal decision-making behavior and interaction of different stakeholders, constructs the objective functions of stakeholder relationship network, applies centrality measure and dominant-set clustering to analyze the optimal conditions of the whole network, and finally carries out simulation calculation. The results show that it is feasible and effective to apply network analysis method to the study of stakeholder relationship in Public-Private Partnership construction projects.
\end{abstract}

\section{Introduction}

Under the background of population aging, the construction of livable communities for the elderly has attracted increasing attention. With the government financial pressure being greater, social capital should be taken into consideration. The Public-Private Partnership (PPP) model is an effective public goods provision method. However, the project organization form of the PPP model is very complicated, and various stakeholders will inevitably have different interests and responsibilities. Thus, the governance research of this type of project is very urgent. The complex network method can be used to study the complex structural relationship of stakeholders. Projects involve a wide array of stakeholders whose interests and demands need to be considered in the managerial decision-making, to ensure the success of the project [1-3]. The elderly livable community construction project belongs to Public-Private Partnership projects. The Public-Private Partnership (PPP) model is an innovative model in which the government and social capital establish a partnership of benefit-sharing and risk-sharing and jointly provide public products and services. The organization form of the PPP project is very complicated. It is necessary to pay attention to the differences in the interests and responsibilities of multiple stakeholders.

By conducting stakeholder analysis, this paper attempts to build a "correct" picture of the complex stakeholders' relation upon which the organizational action concerning stakeholders can be determined. Building the "correct" picture of the stakeholder relationship, however, is not as straightforward as diverse normative managerial methods and tools of stakeholder analysis would suggest. This kind of PPP construction project has long duration and a large number of stakeholders. They play different roles and have influence on each other in different periods of the project. The complex network method can be used to study this kind of complex structural relation among stakeholders. This theory usually explains the relation between individuals and the collective behavior of the system, in which there are different individuals with a large number of interactions [4]. 
Therefore, in the context of population ageing, this paper takes the Qingdao elderly livable community construction project as an example. From the perspective of governance, complex network method is applied to the stakeholder relation analysis and the multiple stakeholders' relation network model is established. This model uses variational inequality to analyze the optimal conditions of the stakeholder relationship network. On the basis of stakeholder theory and complex network theory, this paper identifies the network node and measures the relation strength among different stakeholders. Based on this, the stakeholder network model is established. It can be seen from the results that the key role of the relationship governance is the government departments. The purpose of the authority should focus on decentralization, management, and service. In addition, the idea of the PPP construction project should change from ability to demand, which means motivating users' deep participation.

The innovations of this paper are as follows: (1) from the perspective of research, in addition to considering dual relationship, multiple-stakeholder relation is also considered. (2) In terms of research content, this paper aims at the elderly livable community construction project, which explores the PPP model and the integration of medical care and elderly care. (3) In the research method, we apply graph theoretical analysis including centrality measure and dominant-set clustering to figure out the importance of each stakeholder in the relational network. (4) As for the research results, this paper draws the conclusion through simulation: the private investment company, the PPP project management company, the civil affairs bureau, the financial bureau, and the health commission become the dominant set. Thus, the mission to serve the elderly and make them more livable can be guaranteed. Additionally, the user stakeholder is put into the dominant set in the relationship network, which aims to motivate users' deep participation. It is the reply to the idea and purpose of this PPP construction project.

\section{Literature Review}

The relevant literature should be reviewed here to clarify the necessity for our study. In order to demonstrate the contributions in detail, we explore the literature mainly involving the following two subsections.

2.1. Related Research on Stakeholder Theory. The stakeholder theory has two core issues: one is the stakeholder identification and the other is stakeholder saliencies [5]. Stakeholder theory provides a solid basis for the identifying, classifying, and categorizing of the multiple stakeholders, as well as understanding their behavior. The basic point of view of stakeholder theory is that the organization does have a relationship with lots of constituent groups and that it could engender and maintain the support of these groups by considering and balancing their relevant interests $[6,7]$. In general, the main purpose of stakeholder theory is to enable project managers to understand and, subsequently, manage stakeholders more strategically. While it originated in the field of strategic management, stakeholder theory has been applied to a large number of other fields. Furthermore, the theory has been presented and used in a lot of ways that are quite distinct and involve pretty different methodologies, concepts, types of evidence, and criteria of appraisal [8]. The managerial importance of stakeholder management has been accentuated in various studies [9-11] which demonstrate that the fair treatment of stakeholders is related to long-run survival of the organizations. Since the landmark book on stakeholder management was published [6], stakeholder theory has been thoroughly debated. The majority of research on stakeholders has focused on theoretical discussions and debates about the concept of stakeholders and the nature of stakeholder theory [5-8, 12, 13]. Actually, the theory has been extensively developed, which has resulted in a diverse series of definitions and perspectives. Among others, scholars have called for the application of the ideas of stakeholder theory to real-world problems instead of focusing solely on the development of the theory [14].

The management of project stakeholders by taking their needs and requirements into account is an essential element of project success [1]. In the project management standard [15], stakeholders are defined broadly as "individuals and organizations that are actively involved in the project or whose interest may be affected as a result of project execution or project completion." A typical division is to group stakeholders into internal and external stakeholders. Internal stakeholders are the stakeholders that are formal members of the project coalition and, hence, usually support the project [16]. They are often referred to as primary stakeholders [17] or business actors [18]. Such stakeholders usually have a formal, official, or contractual relation with the organization. External project stakeholders are not formal members of the project coalition but may have effects on the project or be affected by it. Such groups are often referred to as non-business stakeholders [18] or secondary stakeholders. The other division is to group stakeholders into positive and passive stakeholders [9]. On the basis of social distance dimension, another division is to group stakeholders into first-level social stakeholders, second-level social stakeholders, first-level non-social stakeholders, and second-level non-social stakeholders [19]. A lack of understanding of the multiple stakeholders, the drivers of stakeholders' actions and potential to influence during the construction project life cycle, especially on the part of relation governance, has been treated as a major problem in projects [20-22]. Recently, both internal and external pressures for construction projects to be more environmentally friendly and socially responsible have been on the rise. Nowadays, the concerns of external stakeholders need to be taken into consideration in the project decisionmaking in order to ensure the construction project success [20]. However, in the project management field, most scholars have devoted much of their research efforts to examining the management of direct stakeholders that are important with regard to the construction project's economic interests, including investors, suppliers, and builders. Project stakeholder analysis is a central part of stakeholder management. It is the process through which we attempt to 
understand and analyze the project's stakeholders' interaction in order to be able to determine the right type of action concerning different stakeholders [4].

The interaction mechanism among different stakeholders has not been studied in depth. From the perspective of project governance, the governance of PPP construction project is mainly focused on contract governance. Through a series of formal contract arrangements, the responsibilities and rights of multiple stakeholders are matched, but this kind of governance cannot solve all problems. Therefore, in the current situation of focusing too much on contract governance, researching on stakeholder relation governance and governance strategies can make up for the lack of contract governance, effectively coordinate the relation among multiple stakeholders, improve project governance performance, and ultimately achieve project goals.

2.2. Social Network Analysis Research. Social network refers to a collection of actors and various relationships that connect them, such as friendship, communication, and suggestions. It embodies a structural relationship, which can reflect the social relation between actors [23]. Since social network analysis emphasized the interpretation of behavior in accordance with the structural constraints of behavior rather than the internal drive of the actors, the social network theorists tended to focus on the structural characteristics of the network. Social network analysis was used to discuss the strategy of stakeholder pressure $[4,12]$. Through analysis of three European project cases, social network analysis could visually show the structure of the project task set and project governance framework [24]. The organization was a network system composed of multiple stakeholders. Social network analysis technology could be used to dig out characteristics of the organizational network and applied it to organization management of R\&D team [25]. Social network analysis was introduced into the management of project organization, which was composed of many stakeholders, and the transmission of information and resources between the organizations is based on the network structure. Therefore, social network analysis could be applied to explain the relation of multiple stakeholders of the project [26]. Based on the project management of complex network theory, Ding et al. built a project governance network model for large-scale construction supervision projects to analyze the embedding methods of stakeholders, the characteristics of network structure, and the interaction among governance strategies [27]. On the basis of social network analysis, Le focused on the large-scale infrastructure PPP projects and analyzed the stakeholder relation [28]. Sun used SNA to build a social network model of the cooperative relation between the stakeholders of the agent construction project. The path to project cooperative relation improvement was explored by analyzing the network structure of multiple cooperative relationships among stakeholders [29]. Based on SNA, Li et al. summarized eight types of social network elements of large-scale engineering project organization and established a quantitative analysis method to calculate the close relationship, small team, centrality, and other indicators of large-scale engineering project organization [30]. From the perspective of frame design, Pan et al. aimed at large-scale and complex project organization network and put forward related concepts, research procedures, network model construction and analysis indicators, etc. [31].

There are four methods commonly used for data collection in social network analysis, including full network, snowball, egocentric networks with altered connections, and egocentric networks-ego only [32]. Scholars focused on the index research of relation strength. Based on strength of ties, four dimensions were put forward, including communication time, depth of feeling, familiarity, and reciprocity [33]. Other indexes were considered, including sociality [5], advice given/received [34], breadth of topics [33], voluntary investment in the tie [35], trust [36], commitment [37], intimacy [5], intensity of support [38], and frequency [39].

To sum up, the PPP model of the elderly livable community construction project has drawn certain attention in the existing literature. However, most of them are discussed from a macro perspective. The analysis framework lacks a clear theoretical basis. Furthermore, the current research related to the elderly livable community construction project and the stakeholder relation focuses on the optimization of the dual relationship, while the research on multiple stakeholders' benefits sharing and risk sharing is less.

\section{Problem Description and Symbol Definition}

Sociogram method is applied to social network analysis. In sociogram, nodes are used to represent the actors, and edges are used to represent the relation between each actor or the bridge connecting the actors. In the PPP construction project, the social network is composed of all stakeholders. Stakeholder identification should be considered in the process of the social network construction. Stakeholder relation network is built on the basis of trust and contracts. Accordingly, undirected graph is suitable for this network. Furthermore, the stakeholder relation and its effects on different stakeholder's behavior should be obviously shown in this relation network. Weighted graph is considered to describe the strength of stakeholder relationship.

Through the analysis above, the obtained relation network for the interested groups in the government funded project is an undirected weighted graph. Let $w(i, j)$ be the weight for the link between $i$ and $j$, and $w(i, j)=w(j, i)$; then, the network is mathematically denoted by $G=\{V, E, W\}$. Here, $V(G)$ is the set $N=\{1,2,3, \ldots, n\}$ representing the interested groups in the project; $E$ is the set for the links representing the relation among the interested groups; and $e_{i j}$ is the link between $i, j$ and $e_{i j}=e_{j i}$. The notations are as follows:

$$
\begin{array}{r}
V=\{i: i \in N\}, \\
E=\left\{e(i, j) \mid t i n \neq q j h_{,} x, 7 j C \in ; N\right\}, \\
W=\left\{w(i, j) \mid t i n \neq q j h_{i} x, 7 j C \in ; N\right\} .
\end{array}
$$

If there are too many nodes in the network and they overlap a lot, matrix method should be considered. The 
matrix method can be used to find the intersection of the corresponding elements and clearly show the relation between the corresponding elements. Adjacency matrix is applied to the research on stakeholder relation network of construction project. Each element in the matrix represents whether there is a relation between two nodes and the strength of the relation.

If two vertices are connected by a link, then they are adjacent, or called neighbors in the graph. The adjacency matrix $A=\left[a_{i j}\right]$ is defined such that if $(i, j) \in E$; then, $a_{i j}=1$; and if $(i, j) \notin E$, then, $a_{i j}=0 . w_{i j}$ denotes the weight between $i, j$, representing the strength of the connection, and $0 \leq w_{i j} \leq w_{M}$, where $w_{M}$ is the upper bound for $w_{i j}$. The row sum and column sum of the adjacency matrix represent the degree of the corresponding vertices.

Both the sociogram and matrix method are applied to the stakeholder relation analysis in this paper. The flowchart is shown in Figure 1.

\section{Establishment of Stakeholder Network Model}

4.1. Stakeholder Identification. On the basis of contract, participation, and influence, the concept of stakeholders is defined. The three-dimension model, including process dimension, task dimension, and role dimension, can be used to identify the stakeholders [27]. Then, this paper applies snowball method to collect network node data. Through the analysis above, the different stakeholders involved in the Qingdao elderly livable community construction project are identified here. The stakeholder network nodes are composed of authority, investor, project manager, consultant, supervisor, designer, contractor, supplier, related management departments, and the public [24, 27, 40]. The detailed information of the stakeholders is shown in Table 1 .

4.2. Stakeholder Network Modeling. The relation data collection was completed through questionnaires and interviews. With the permission of the authority and related participants, we muster the basic situation of all stakeholders and their relations. Likert Scale is applied to describe the strength of ties between different stakeholders.

The relationship among the stakeholders of the project can be modeled as a network $G$. Each stakeholder is denoted by a vertex, and the set of vertices is $V=\left(P_{1}, P_{2}, \ldots, P_{n}\right)$ for the network. The relation between a pair of stakeholders $\left(P_{i}, P_{j}\right)$, if exists, is denoted by a link $e_{i j}$. In this project, there are 16 stakeholders, which are labeled from 1 to 16 . An illustration of the network is shown in Figure 2.

4.3. Stakeholder Network Analysis. A quantitative analysis of the network structure requires the adjacency matrix $A$. The entries $\left(a_{i j}\right)$ of $A$ is defined as

$$
a_{i j}= \begin{cases}1, & \text { if } e_{i j} \text { exists } \\ 0, & \text { otherwise. }\end{cases}
$$

The adjacency matrix for the network as shown in Figure 2 is shown in Table 2.

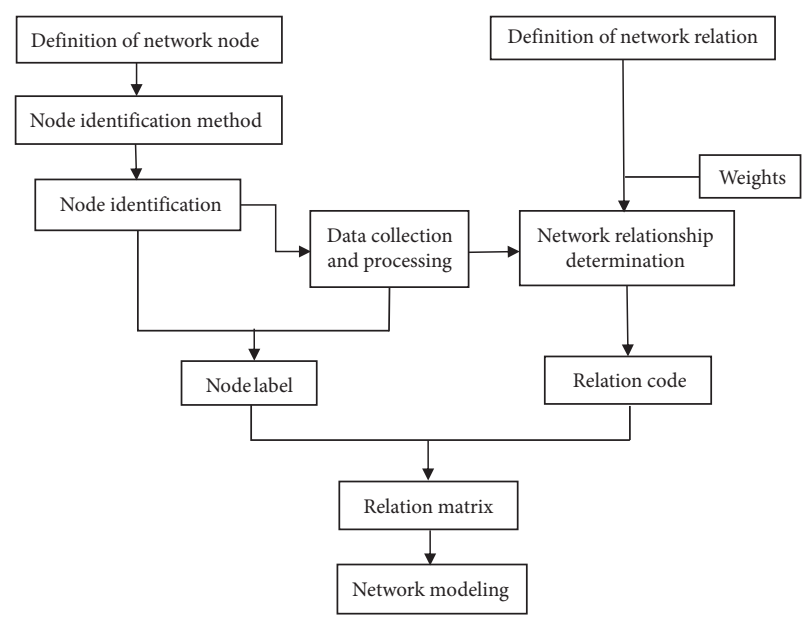

Figure 1: Flowchart of stakeholder relation network modeling.

Given the links between pairs of vertices, we can characterize the topological structure of the network. There are several methods of measuring centrality in network theory, including eigenvector centrality, closeness centrality, betweenness centrality, and degree centrality. Degree centrality is the number of edges of the vertex, which is too simple to characterize the complex relationship. Closeness centrality is the inverse of the sum of all shortest paths to other vertices. It strongly favors the vertices that are connected to many other vertices one or two hops away but is less favorable to vertices that are strongly connected to the hub of the network. Eigenvector centrality is based on the eigenvectors of the affinity matrix, which cost much more computation for complex network. We observe that there are some so-called core vertices that are "influential" in the network; that is, they are within short paths away from many other vertices. A useful quantity is the "coreness" for the vertices. It can be defined through the concept of $k$-core, which is the largest subnetwork where each vertex has at least $k$ links. The coreness of a vertex is set to be $k$ if it belongs to a $k$-core but not a $(k+1)$-core. The coreness can be used to quantify the centrality of the centrality of the vertices. It is evident that a vertex of coreness number $k$ also belongs to $(k-1)$-core, so a shell structure of the network can be discovered through the coreness number of vertices, which is illustrated in Figure 3 . We see that $P_{1}, P_{2}, \ldots, P_{7}, P_{9}, \ldots, P_{12}$ have coreness 10, $P_{8}$ has coreness 9 , and the rest of the vertices have coreness 7 . This demonstrates that the stakeholders of the project are highly connected to each other.

In order to describe not only the connectivity but also the closeness between pairs of vertices in the network, the affinity matrix $W=\left(w_{i j}\right)$ associated with the network is needed, where $w_{i j}$ denotes the weight for the link $e_{i j}$ if it exists. The weight $w_{i j}$ models the closeness between the vertices $\left(P_{i}, P_{i}\right)$; the larger the weight, the closer the connection. There are multiple ways to quantify the weights. An inherent way of defining the weight is through the betweenness of the network. Let $g_{l k}$ be the total number of shortest paths between vertices $P_{l}, P_{k}$, and $g_{l k}\left(e_{i j}\right)$ be the number of shortest paths containing $e_{i j}$. Then, the 
TABLE 1: Stakeholders of the elderly livable community construction project.

\begin{tabular}{lcc}
\hline Stakeholder category & Label & Stakeholder name \\
\hline Authority & 1 & Municipal government and construction committee \\
Investor & 2 & Private investment company \\
Project manager & 3 & PPP project management company \\
Consultant & 4 & Consulting company \\
Supervisor & 5 & Supervision company \\
Designer & 6 & Design company \\
Contractor & 7 & Contractor \\
Supplier & 8 & Supplier \\
& 9 & Civil affairs bureau \\
& 10 & Finance bureau \\
Related management departments & 11 & Health committee \\
& 12 & Audit bureau \\
Public & 13 & Work safety bureau \\
& 14 & Environmental protection bureau \\
\end{tabular}

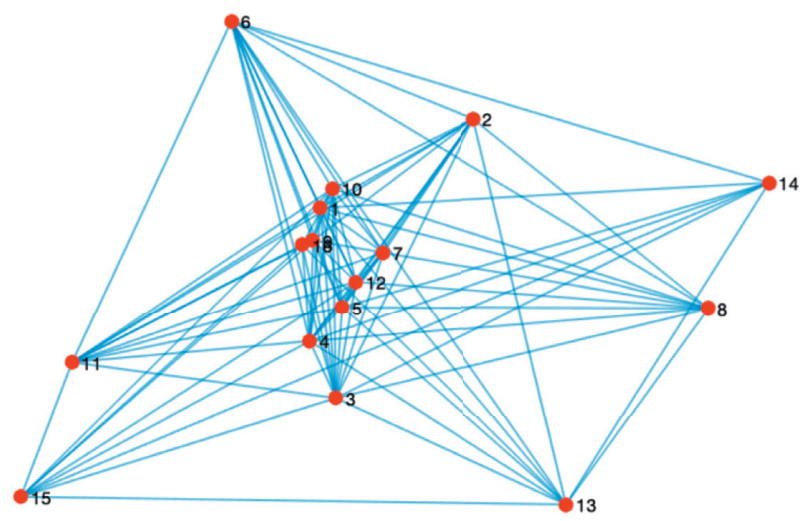

FIGURE 2: The network showing the connections among the stakeholders.

betweenness of two adjacent vertices $P_{i}, P_{j}$ introduced in [1] is defined by

$$
B_{i j}=\sum_{l, k} \frac{g_{l k}\left(e_{i j}\right)}{g_{l k}} .
$$

High betweenness between $P_{i}, P_{j}$ indicates the high disparity between the neighbors of the two vertices, so the closeness between the two vertices is considered to be low. Therefore, we can define the weight as [2] $w_{i j}=1 / B_{i j}$ for two adjacent vertices $P_{i}, P_{j}$. The obtained affinity matrix is displayed in Table 3 .

Another way of defining the closeness of pairs of vertices is through domain knowledge and expert opinion. For example, we obtain the following affinity matrix defined by expert opinion, which is displayed on the right of Table 3.

Based on the closeness of pairs of vertices, we consider the clustering of vertices. That is, we would like to extract maximally coherent groups of vertices from the network. These coherent groups indicate stakeholders that share the
TABLe 2: The adjacency matrix for the network.

\begin{tabular}{|c|c|c|c|c|c|c|c|c|c|c|c|c|c|c|c|c|}
\hline 1 & 0 & 1 & 1 & 1 & 1 & 1 & 1 & 1 & 1 & 1 & 1 & 1 & 1 & 1 & 0 & 0 \\
\hline 2 & 1 & 0 & 1 & 1 & 1 & 1 & 1 & 1 & 1 & 1 & 1 & 1 & 1 & 0 & 0 & 0 \\
\hline 3 & 1 & 1 & 0 & 1 & 1 & 1 & 1 & 1 & 1 & 1 & 1 & 1 & 1 & 1 & 1 & 1 \\
\hline 4 & 1 & 1 & 1 & 0 & 1 & 1 & 1 & 1 & 1 & 1 & 1 & 1 & 1 & 1 & 1 & 1 \\
\hline 5 & 1 & 1 & 1 & 1 & 0 & 1 & 1 & 1 & 1 & 1 & 1 & 1 & 1 & 1 & 0 & 0 \\
\hline 6 & 1 & 1 & 1 & 1 & 1 & 0 & 1 & 1 & 1 & 1 & 1 & 1 & 1 & 1 & 0 & 0 \\
\hline 7 & 1 & 1 & 1 & 1 & 1 & 1 & 0 & 1 & 1 & 1 & 1 & 1 & 0 & 0 & 0 & 0 \\
\hline 8 & 1 & 1 & 1 & 1 & 1 & 1 & 1 & 0 & 0 & 1 & 0 & 1 & 1 & 0 & 0 & 0 \\
\hline 9 & 1 & 1 & 1 & 1 & 1 & 1 & 1 & 0 & 0 & 1 & 1 & 1 & 0 & 0 & 1 & 1 \\
\hline 10 & 1 & 1 & 1 & 1 & 1 & 1 & 1 & 1 & 1 & 0 & 1 & 1 & 0 & 0 & 1 & 1 \\
\hline 11 & 1 & 1 & 1 & 1 & 1 & 1 & 1 & 0 & 1 & 1 & 0 & 1 & 0 & 0 & 1 & 1 \\
\hline 12 & 1 & 1 & 1 & 1 & 1 & 1 & 1 & 1 & 1 & 1 & 1 & 0 & 0 & 0 & 1 & 0 \\
\hline 13 & 1 & 1 & 1 & 1 & 1 & 1 & 0 & 1 & 0 & 0 & 0 & 0 & 0 & 1 & 1 & 1 \\
\hline 14 & 1 & 0 & 1 & 1 & 1 & 1 & 0 & 0 & 0 & 0 & 0 & 0 & 1 & 0 & 1 & 0 \\
\hline 15 & 0 & 0 & 1 & 1 & 0 & 0 & 0 & 0 & 1 & 1 & 1 & 1 & 1 & 1 & 0 & 1 \\
\hline 16 & 0 & 0 & 1 & 1 & 0 & 0 & 0 & 0 & 1 & 1 & 1 & 0 & 1 & 0 & 1 & 0 \\
\hline
\end{tabular}

same interests. In this paper, we partition the vertices into two groups, called internal set $S$ and external set $S^{c}$. Authors in [3] propose the concept of dominant set that effectively finds the clique $S$ such that both $S$ and $S^{c}$ have homogeneity. More exactly, they introduce the weight of a vertex $P_{i}$ with respect to a clique $S$ as

$$
w_{S}(i)= \begin{cases}1, & \text { if }|S|=1, \\ \sum_{j \in S \backslash\{i\}} \phi_{S \backslash\{i\}}(j, i) w_{S \backslash\{i\}}(j), & \text { otherwise, }\end{cases}
$$

where $\phi_{S \backslash\{i\}}(j, i)=w_{i j}-1 /(|S|-1) \sum_{l \in S \backslash\{i\}} w_{i l}$. $S$ is said to be a dominant set if

(i) $w_{S}(i)>0$ for all $i \in S$

(ii) $w_{S \cup\{j\}}(j)<0$ for all $j \in S^{c}$ 


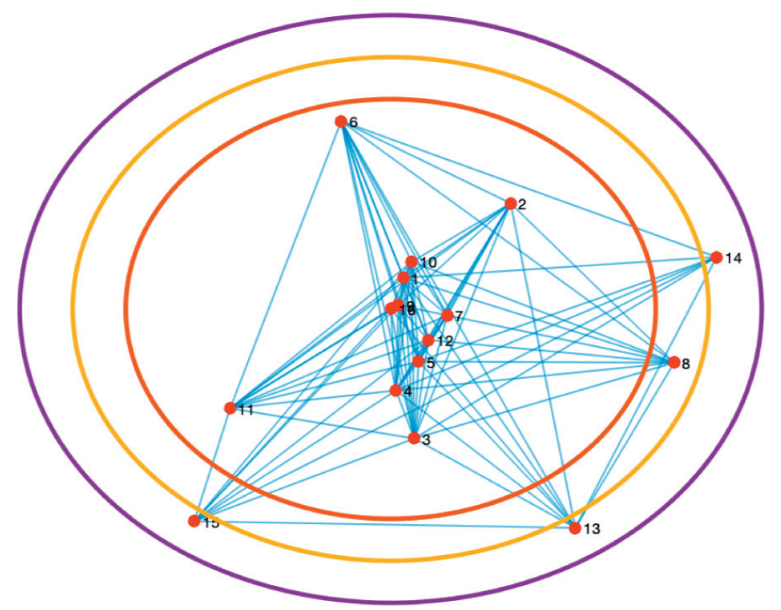

Figure 3: Coreness of the vertices. From inner to outer, the coreness is equal to 10,8 , and 7 , respectively.

Table 3: The affinity matrix defined through the betweenness of pairs of vertices (left) and expert opinion (right).

\begin{tabular}{|c|c|c|c|c|c|c|c|c|c|c|c|c|c|c|c|c|}
\hline & & & & 4 & 5 & & & & & 10 & 11 & 12 & 13 & 14 & 15 & 16 \\
\hline & & 1.00 & 1.00 & 1.00 & 1.00 & 1.00 & 1.00 & 1.00 & 1.00 & 1.00 & 1.00 & 1.00 & 1.00 & 1.00 & 0.12 & 0.17 \\
\hline & 1.00 & 0.00 & 1.00 & 1.00 & 1.00 & 1.00 & 1.00 & 1.00 & 1.00 & 1.00 & 1.00 & 1.00 & 1.00 & 0.17 & $\mid 0.14$ & 0.17 \\
\hline & 1.00 & 1.00 & 0.00 & 1.00 & 1.00 & 1.00 & 1.00 & 1.00 & 1.00 & 1.00 & 1.00 & 1.00 & 1.00 & 1.00 & 1.00 & 1.00 \\
\hline & 1.00 & 1.00 & 1.00 & 1.00 & 1.00 & 1.00 & 1.00 & 1.00 & 1.00 & 1.00 & 1.00 & 1.00 & 1.00 & 1.00 & 1.00 & 1.00 \\
\hline & 1.00 & 1.00 & 1.00 & 1.00 & 1.00 & 1.00 & 1.00 & 1.00 & 1.00 & 1.00 & 1.00 & 1.00 & 1.00 & 1.00 & 0.12 & \begin{tabular}{|l|}
0.11 \\
\end{tabular} \\
\hline & 1.00 & 1.00 & 1.00 & 1.00 & 1.00 & 1.00 & 1.00 & 1.00 & 1.00 & 1.00 & 1.00 & 1.00 & 1.00 & 1.00 & 0.12 & \begin{tabular}{|l|}
0.1 \\
\end{tabular} \\
\hline & 1.00 & 1.00 & 1.00 & 1.00 & 1.00 & 1.00 & 1.00 & 1.00 & 1.00 & 1.00 & 1.00 & 1.00 & 0.14 & 0.20 & 0.17 & 0.20 \\
\hline & 1.00 & 1.00 & 1.00 & 1.00 & 1.00 & 1.00 & 1.00 & 1.00 & 0.11 & 1.00 & 0.11 & 1.00 & 1.00 & 0.17 & 0.20 & 0.25 \\
\hline & 1.00 & 1.00 & 1.00 & 1.00 & 1.00 & 1.00 & 1.00 & 0.11 & 1.00 & 1.00 & 1.00 & 1.00 & 0.12 & 0.17 & 1.00 & 1.00 \\
\hline & 1.00 & 1.00 & 1.00 & 1.00 & 1.00 & 1.00 & 1.00 & 1.00 & 1.00 & 1.00 & 1.00 & 1.00 & 0.11 & 0.17 & 1.00 & 1 \\
\hline & 1.00 & 1.00 & 1.00 & 1.00 & 1.001 & 1.00 & 1.00 & 0.11 & 1.00 & 1.00 & 1.00 & 1.00 & 0.12 & 0.17 & 1.00 & 1.00 \\
\hline & 1.00 & 1.00 & 1.00 & 1.00 & 1.00 & 1.00 & 1.00 & 1.00 & 1.00 & 1.00 & 1.00 & 1.00 & 0.12 & 0.17 & 1.00 & 0.17 \\
\hline & 1.00 & 1.00 & 1.00 & 1.00 & 1.00 & 1.00 & 0.14 & 1.00 & 0.12 & 0.11 & 0.12 & 0.12 & 1.00 & 1.00 & 1.00 & 1.00 \\
\hline & 1.00 & 0.17 & 1.00 & 1.00 & 1.00 & 1.00 & 0.20 & 0.17 & 0.17 & 0.17 & 0.17 & $0.17 \mid$ & 1.00 & 1.00 & 1.00 & 0.25 \\
\hline & 0.12 & 0.14 & 1.00 & 1.00 & 0.12 & 0.12 & 0.17 & 0.20 & 1.00 & 1.00 & 1.00 & 1.00 & 1.00 & 1.00 & 1.00 & 1.00 \\
\hline & 0.17 & 0.17 & 1.00 & 1.00 & 0.17 & 0.17 & 0.20 & 0.25 & 1.00 & 1.00 & 1.00 & $\mid 0.17$ & 1.00 & 0.25 & 1.00 & 1.00 \\
\hline & 1 & 2 & 3 & 4 & 5 & & 7 & 8 & 9 & 10 & 11 & 121 & 13 & 14 & 15 & 16 \\
\hline 1 & 0 & 4 & 4 & 4 & 4 & & 3 & 3 & 2 & & & & & 1 & 0 & \\
\hline 2 & 4 & 0 & 3 & & & & & & 2 & & & & & 0 & 0 & 0 \\
\hline 3 & 4 & 3 & 0 & 4 & 4 & 3 & 4 & 3 & 3 & 4 & & 2 & 1 & 1 & 2 & 1 \\
\hline 4 & 4 & 4 & 4 & 0 & 3 & 3 & 2 & 2 & 3 & 4 & 3 & 2 & 2 & 1 & 2 & 1 \\
\hline 5 & 4 & 4 & 4 & 3 & 0 & 3 & 4 & 3 & 2 & 4 & 2 & 3 & 2 & 1 & 0 & 0 \\
\hline 6 & 3 & 3 & 3 & 3 & 3 & 0 & 4 & 3 & 1 & 3 & 1 & 2 & 1 & 1 & 0 & 0 \\
\hline 7 & 3 & 4 & 4 & 2 & 4 & 4 & 0 & 4 & 2 & 3 & 2 & 2 & 0 & 0 & 0 & 0 \\
\hline 8 & 3 & 3 & 3 & 2 & 3 & 3 & 4 & 0 & 0 & 1 & 0 & 1 & 1 & 0 & 0 & 0 \\
\hline 0 & 2 & 2 & 3 & 3 & 2 & & 2 & 0 & 0 & 3 & & 2 & 0 & 0 & 3 & 4 \\
\hline & 4 & 3 & 4 & & & & & & 3 & 0 & & & & & & 1 \\
\hline & 2 & 2 & 4 & & 2 & & & & 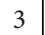 & & & 2 & 0 & 0 & 3 & 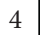 \\
\hline & 3 & 3 & 2 & 2 & 3 & 2 & 2 & 1 & 2 & 3 & 2 & 0 & 0 & 0 & 1 & 0 \\
\hline & 2 & 1 & 1 & 2 & 2 & 1 & 0 & 1 & 0 & 0 & 0 & 0 & 0 & 1 & 1 & 1 \\
\hline & 1 & 0 & 1 & 1 & 1 & 1 & 0 & 0 & 0 & 0 & 0 & 0 & 1 & 0 & 1 & 0 \\
\hline & 0 & 0 & 2 & 2 & 0 & 0 & 0 & 0 & 3 & 2 & 3 & 1 & 1 & 1 & 0 & 3 \\
\hline & 0 & 0 & 1 & 1 & 0 & 0 & 0 & 0 & 4 & 1 & 4 & 0 & 1 & 0 & 3 & 0 \\
\hline
\end{tabular}

The authors in [3] find that the dominant sets are in oneto-one correspondence to the solutions to the quadratic optimization problem (QP):

$$
\max _{x \in \Delta} x / W x .
$$

The algorithm for solving this problem is

$$
(x(t+1))_{i}=(x(t))_{i} \frac{(A x(t))_{i}}{x(t)^{T} A x(t)},
$$

where $\Delta$ is the standard simplex and the solution $x$ is the probability distribution of the vertices belonging to the dominant set. The computation results of the solution $x$ for the affinity matrices defined in Table 3 are shown on the left and right of Figure 4.

We see that, for the affinity matrix obtained thought the betweenness of pairs of vertices, $P_{1}, P_{2}, \ldots, P_{7}, P_{9}, \ldots, P_{12}$ are in the dominant set, while for the affinity matrix by expert opinion, $P_{1}, P_{2}, \ldots, P_{5}, P_{7}, P_{10}$ belong to the dominant set.

\section{Simulation and Result Analysis}

In this project, we look for the situation when $P_{2}, P_{3}, P_{9}, P_{10}, P_{11}$ become the dominant set. We achieve it by simulating with various affinity matrices, in particular increasing the weights for the links to the vertices that are assigned to the dominant set or decreasing the weights for the links to non-dominant set vertices. For example, we decrease the weights for the links to $P_{1}$ and obtain an affinity matrix with the probability of vertices belonging to the dominant set as shown in Figure 5. We see that in this case $P_{2}, P_{3}, P_{4}, P_{5}, P_{9}, P_{10}, P_{11}$ are in the dominant set, which satisfies our need.

Further, we want to put $P_{16}$ into the dominant set by increasing the weights for the links to it. The result is shown in Figure 6.

The notion of coreness mentioned earlier can be generalized to weighted graph. In particular, a $k$-core is the largest subnetwork that each vertex has total weight of at least $k$. We compute the coreness of vertices of the network with the affinity matrix defined in Figure 6. An illustration of the coreness of vertices is shown in Figure 7. We see that the 


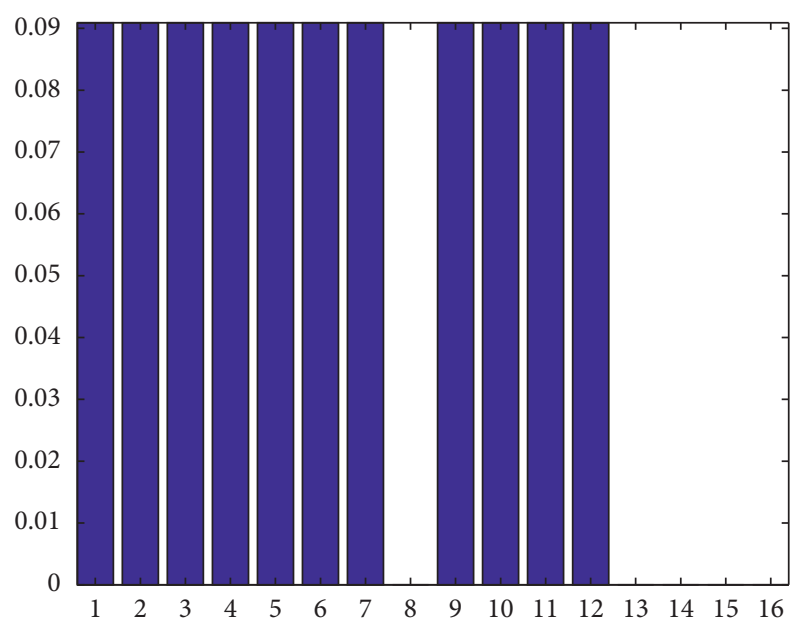

(a)

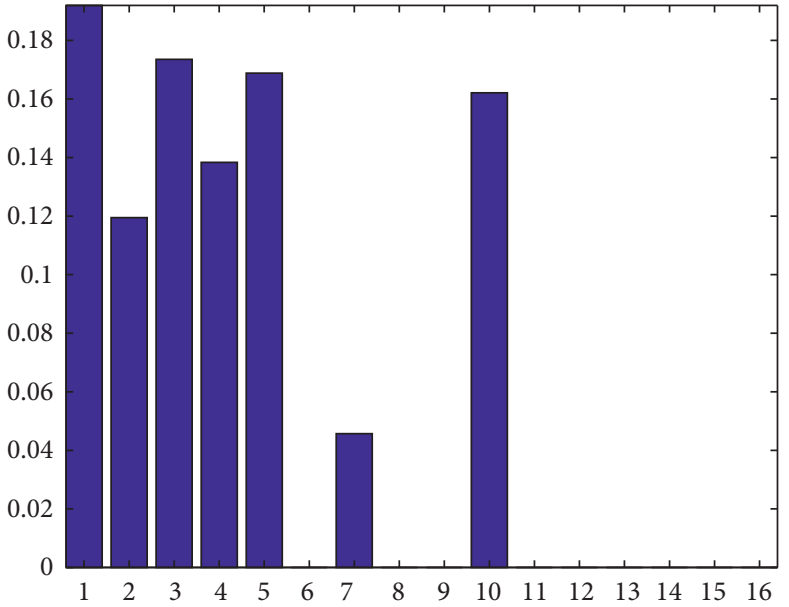

(b)

FIgURe 4: The probability of vertices belonging to the dominant set (S). The horizontal axis is the labels of the vertices, and the vertical axis is for the probability.

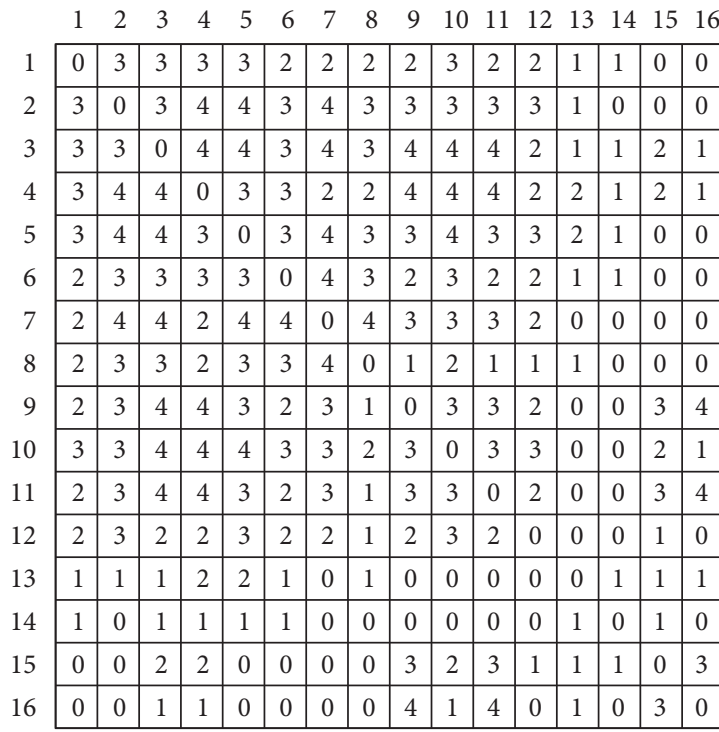

(a)

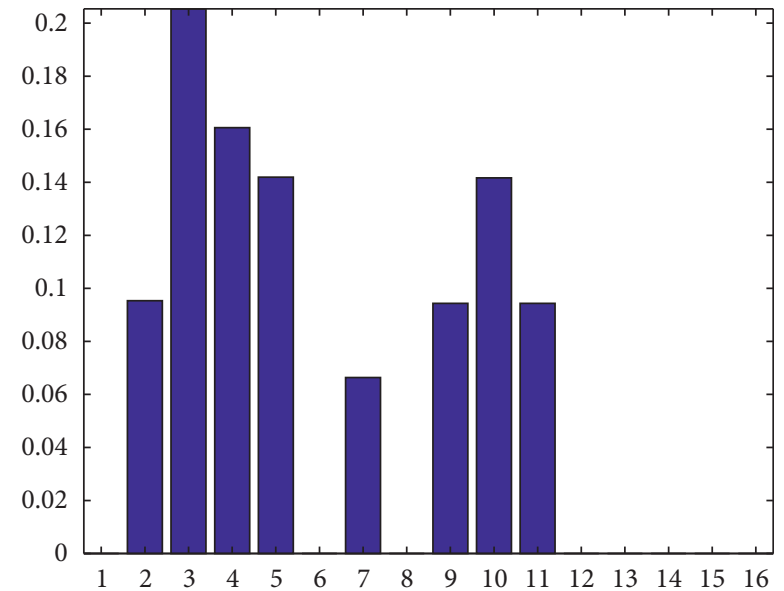

(b)

Figure 5: (a) The affinity matrix obtained in the simulation. (b) The probability of belonging to the dominant set given the affinity matrix.

coreness of $P_{1}, \ldots, P_{7}, P_{9}, P_{10}, P_{11}, P_{16}$ is 25 , the coreness of $P_{8}, P_{12}$ is 24 , and the coreness of $P_{15}, P_{13}, P_{14}$ is 17,11 , and 10 , respectively.

From the simulation result, we see that, as the authority's relations with other stakeholders become weaker, some important government departments become central stakeholders in this construction project. And if we strengthen the ties between the users and the related stakeholders, the users are getting into the core group. 


\begin{tabular}{|c|c|c|c|c|c|c|c|c|c|c|c|c|c|c|c|c|}
\hline & & & 3 & & & & 7 & & & & & & & & & \\
\hline 1 & 0 & 3 & 3 & 3 & 3 & 2 & 2 & 2 & 2 & 3 & 2 & 2 & 1 & 1 & 0 & 3 \\
\hline 2 & 3 & 0 & 3 & 4 & 4 & 3 & 4 & 3 & 3 & 3 & 3 & 3 & 1 & 0 & 0 & 4 \\
\hline 3 & 3 & 3 & 0 & 4 & 4 & 3 & 4 & 3 & 4 & 4 & 4 & 2 & 1 & 1 & 2 & 3 \\
\hline 4 & 3 & 4 & 4 & 0 & 3 & 3 & 2 & 2 & 4 & 4 & 4 & 2 & 2 & 1 & 2 & 4 \\
\hline 5 & 3 & 4 & 4 & 3 & 0 & 3 & 4 & 3 & 3 & 4 & 3 & 3 & 2 & 1 & 0 & 3 \\
\hline 6 & 2 & 3 & 3 & 3 & 3 & 0 & 4 & 3 & 2 & 3 & 2 & 2 & 1 & 1 & 0 & 0 \\
\hline 7 & 2 & 4 & 4 & 2 & 4 & 4 & 0 & 4 & 3 & 3 & 3 & 2 & 0 & 0 & 0 & 0 \\
\hline 8 & 2 & 3 & 3 & 2 & 3 & 3 & 4 & 0 & 1 & 2 & 1 & 1 & 1 & 0 & 0 & 0 \\
\hline 9 & 2 & 3 & 4 & 4 & 3 & 2 & 3 & 1 & 0 & 3 & 3 & 2 & 0 & 0 & 3 & 4 \\
\hline 0 & 3 & 3 & 4 & 4 & 4 & 3 & 3 & 2 & 3 & 0 & 3 & 3 & 0 & 0 & 2 & 3 \\
\hline 1 & 2 & 3 & 4 & 4 & 3 & 2 & 3 & 1 & 3 & 3 & 0 & 2 & 0 & 0 & 3 & 4 \\
\hline & 2 & 3 & 2 & 2 & 3 & 2 & 2 & 1 & 2 & 3 & 2 & 0 & 0 & 0 & 1 & 0 \\
\hline 3 & 1 & 1 & 1 & 2 & 2 & 1 & 0 & 1 & 0 & 0 & 0 & 0 & 0 & 1 & 1 & 1 \\
\hline 4 & 1 & 0 & 1 & 1 & 1 & 1 & 0 & 0 & 0 & 0 & 0 & 0 & 1 & 0 & 1 & 3 \\
\hline 5 & 0 & 0 & 2 & 2 & 0 & 0 & 0 & 0 & 3 & 2 & 3 & 1 & 1 & 1 & 0 & 4 \\
\hline 6 & 3 & 4 & 3 & 4 & 3 & 0 & 0 & 0 & 4 & 3 & 4 & 0 & 1 & 3 & 4 & 0 \\
\hline
\end{tabular}

(a)

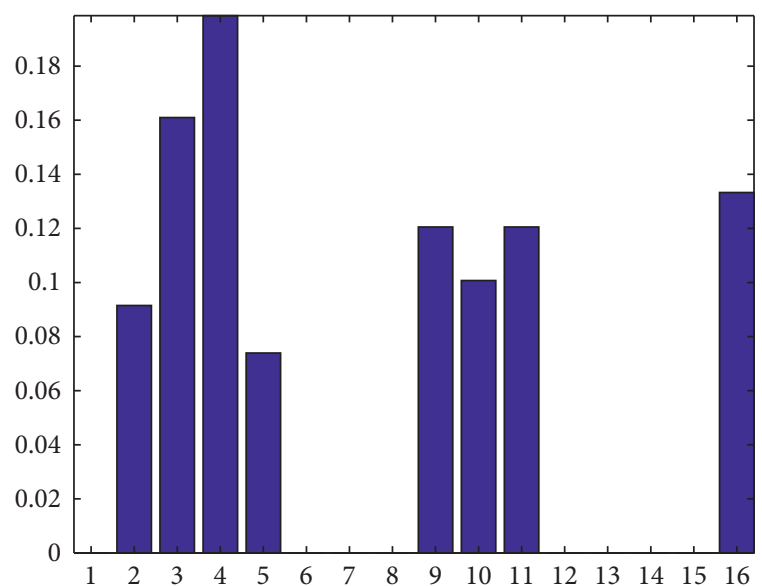

(b)

Figure 6: Affinity matrix (a) and the probability of vertices belonging to the dominant set (b) such that $P_{2}, P_{3}, P_{4}, P_{5}, P_{9}, P_{10}, P_{11}$ and $P_{16}$ are dominant.

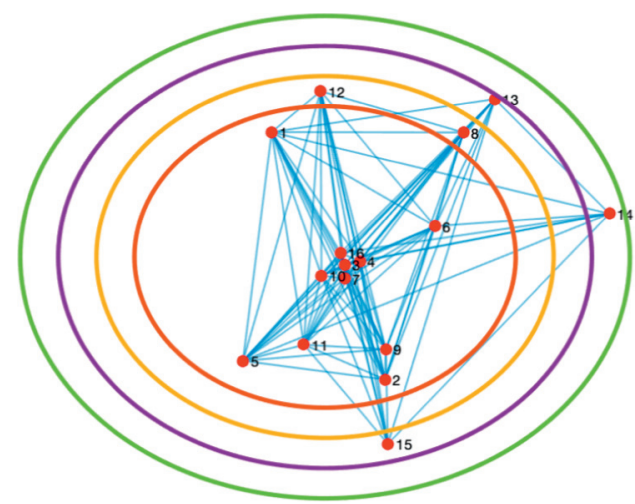

FiguRE 7: The coreness of vertices for the network with affinity matrix in Figure 6. From inner to outer, circles represent coreness equal to 25, $24,17,11$, and 10 , respectively.

\section{Conclusion}

This paper uses the theory of complex networks to study the relationship between stakeholders in the PPP construction project. Based on the stakeholder network model analysis, the quantitative relationship of each stakeholder is revealed. In addition, it provides a theoretical basis for the relationship governance of such projects. From the process perspective, each stakeholder can be identified. It is effective to measure the strength of stakeholder relationship from the four dimensions of trust, commitment, dependence, and interaction intensity. Undirected multi-valued network graph is suitable to show the structure of stakeholder relation in construction projects. Therefore, the process of the stakeholder network is effective and network model reference is provided for the related research. In addition, the stakeholder network is effective in this PPP construction project.
The stakeholder relationship and its structure characteristics can be described through the indicators of the stakeholder network.

Based on the stakeholder relation network analysis in this PPP construction project, we obtain the following results: (1) in this elderly livable community construction project, government departments dominate the relationship and have significant influence on other stakeholders. However, the participation of the civil affairs bureau and health committee is not enough. The timely delegation of the authority is important so that the improper transfer of benefits or rent-seeking behavior can be prevented. Considering the project feature, it is essential to strengthen the relationship between the civil affairs bureau and other stakeholders as well as the health commission and other stakeholders. (2) The government departments, the private investment company, and the PPP project management 
company are the core stakeholders and have a great influence on the others. Using the simulation analysis method, the private investment company, the PPP project management company, the civil affairs bureau, the financial bureau, and the health commission become the dominant set. Thus, the mission to serve the elderly and make them more livable can be guaranteed. (3) The idea of the PPP construction project is changing from ability to demand. The user engagement is so low which leads to the neglect of their real needs for the project. On the basis of the above situation, the user stakeholder is put into the dominant set. It is the proper reply to this idea, which aims to motivate users' deep participation. In addition, the stakeholder relation network optimization analysis discusses the following managerial insights: (1) the relationship network is formed by stakeholders on the basis of contracts. The key to the normal operation of the construction project relies on whether the stakeholders in the network can work together for a unified goal. The stakeholders' different interest must be balanced to complete the PPP project construction. (2) The PPP project has a large amount of engineering, a long construction period, and a lot of stakeholders. Therefore, the project manager should strive to promote mutually beneficial cooperation between all stakeholders. In addition, it is necessary to focus on the communication and collaboration to make sure of the normal operation of the project. (3) At different stages of the PPP construction project, the identification of the key stakeholders and their different influence is vital. In the project bidding stage, the trust and cooperation between the government and other stakeholders should be strengthened. In the construction and operation stage, the PPP project management company should be well connected with other stakeholders. (4) Only by identifying and coordinating the relationship between key stakeholders and the others can managers avoid conflicts of interest. The government department should strengthen the communication between key stakeholders to avoid wasting resources. The practical evidence is provided to enrich the network governance theory through this study.

Expert evaluation method is applied to determine the indicator weights of the relationship strength in this elderly livable community construction project. The objective data for the stakeholder relationship strength research will create a winwin situation if a project experience database is guaranteed.

\section{Data Availability}

The data used to support the findings of this study are included within the article.

\section{Conflicts of Interest}

The authors declare that there are no conflicts of interest regarding the publication of this paper.

\section{Acknowledgments}

This work was supported by the Fundamental Research Funds for the Central Universities (Grant no. CCNU19A06034).

\section{References}

[1] D. I. Cleland, "Project stakeholder management," Project Management Journal, vol. 17, no. 4, pp. 36-44, 1986.

[2] A. Diallo and D. Thuillier, "The success of international development projects, trust and communication: an African perspective," International Journal of Project Management, vol. 23, no. 3, pp. 237-252, 2005.

[3] S. Olander and A. Landin, "Evaluation of stakeholder influence in the implementation of construction projects," International Journal of Project Management, vol. 23, no. 4, pp. 321-328, 2005.

[4] K. Aaltonen, "Project stakeholder analysis as an environmental interpretation process," International Journal of Project Management, vol. 29, no. 2, pp. 165-183, 2011.

[5] R. K. Mitchell, B. R. Agle, and D. J. Wood, "Toward a theory of stakeholder identification and salience: defining the principle of who and what really counts," The Academy of Management Review, vol. 22, no. 4, pp. 853-886, 1997.

[6] R. E. Freeman, "Strategic management: a stakeholder approach," Journal of Management Studies, vol. 29, no. 2, pp. 131-154, 1984.

[7] T. M. Jones and A. C. Wicks, "Convergent stakeholder theory," The Academy of Management Review, vol. 24, no. 2, pp. 206-221, 1999.

[8] T. Donaldson and L. E. Preston, "The stakeholder theory of the corporation: concepts, evidence, and implications," The Academy of Management Review, vol. 20, no. 1, pp. 65-91, 1995.

[9] M. B. E. Clarkson, "A stakeholder framework for analyzing and evaluating corporate social performance," The Academy of Management Review, vol. 20, no. 1, pp. 92-117, 1995.

[10] T. J. Rowley and M. Moldoveanu, "When will stakeholder groups act? an interest- and identity-based model of stakeholder group mobilization," The Academy of Management Review, vol. 28, no. 2, pp. 204-219, 2003.

[11] G. T. Savage, T. W. Nix, C. J. Whitehead, and J. D. Blair, "Strategies for assessing and managing organizational stakeholders," Academy of Management Perspectives, vol. 5, no. 2, pp. 61-75, 1991.

[12] T. J. Rowley, "Moving beyond dyadic ties: a network theory of stakeholder influences," The Academy of Management Review, vol. 22, no. 4, pp. 887-910, 1997.

[13] J. Frooman, "Stakeholder influence strategies," The Academy of Management Review, vol. 24, no. 2, pp. 191-205, 1999.

[14] J. F. Mcvea and R. E. Freeman, "A names-and-faces approach to stakeholder management," Journal of Management Inquiry, vol. 14, no. 1, pp. 57-69, 2005.

[15] K. Lynch, "Project management institute(PMI)," The Quality Assurance Journal, vol. 8, no. 2, pp. 126-128, 2004.

[16] G. Winch, "Models of manufacturing and the construction process: the genesis of re-engineering construction," Building Research \& Information, vol. 31, no. 2, pp. 107-118, 2010.

[17] D. I. Cleland, "Leadership and the project-management body of knowledge," International Journal of Project Management, vol. 13, no. 2, pp. 83-88, 1995.

[18] B. Cova and R. Salle, "Six key points to merge project marketing into project management," International Journal of Project Management, vol. 23, no. 5, pp. 354-359, 2005.

[19] D. Wheeler and M. Sillanpa"a", "Including the stakeholders: the business case," Long Range Planning, vol. 31, no. 2, pp. 201-210, 1998.

[20] J. Phillipson, P. Lowe, A. Proctor, and E. Ruto, "Stakeholder engagement and knowledge exchange in environmental 
research," Journal of Environmental Management, vol. 95, no. 1, pp. 56-65, 2012.

[21] R. Miller, M. Hobday, T. Leroux-demers, and X. Olleros, "Innovation in complex systems industries: the case of flight simulation," Industrial and Corporate Change, vol. 4, no. 2, pp. 363-400, 1995.

[22] G. M. Winch, "Towards a theory of construction as production by projects," Building Research \& Information, vol. 34, no. 2, pp. 154-163, 2006.

[23] M. O. Jackson and A. van den Nouweland, "Strongly stable networks," Games and Economic Behavior, vol. 51, no. 2, pp. 420-444, 2005.

[24] S. Pryke and S. Pearson, "Project governance: case studies on financial incentives," Building Research \& Information, vol. 34, no. 6, pp. 534-545, 2006.

[25] B. Masquefa, "Top management adoption of a locally driven performance measurement and evaluation system: a social network perspective," Management Accounting Research, vol. 19, no. 2, pp. 182-207, 2008.

[26] S. Ferriani, G. Cattani, and C. Baden-Fuller, "The relational antecedents of project-entrepreneurship: network centrality, team composition and project performance," Research Policy, vol. 38, no. 10, pp. 1545-1558, 2009.

[27] R. G. Ding, F. Liu, T. Sun et al., "The study on project governance based on social network analysis_- an example of large construction project supervision," Journal of Chinese Soft Science, vol. 6, pp. 132-140, 2010.

[28] C. Chen, Research on the Construction and Analysis of the Stakeholder Relation Network in Government Investment Project, Shandong University, Jinan, China, 2011.

[29] Q. Sun, Research on Social Network Structure of ConstructionAgent Projects and Impact on the Project Cooperation, Tianjin University of Technology, Tianjin, China, 2014.

[30] Y. K. Li, Y. Le, and Y. J. Lu, "Large scale projects organization controlling mechanisms and empirical study based on SNA," Journal of Tongji University(Natural Science), vol. 39, no. 11, pp. 1715-1719, 2011.

[31] H. Pan and Y. K. Li, "Study on large and complex engineering projects organization based on social network analysis perspective," Science and Technology Management Research, vol. 20, pp. 214-217, 2013.

[32] M. A. M. A. Kermani, A. Aliahmadi, and R. Hanneman, "Optimizing the choice of influential nodes for diffusion on a social network," International Journal of Communication Systems, vol. 29, no. 7, pp. 1235-1250, 2016.

[33] M. S. Granovetter, "The strength of weak ties," American Journal of Sociology, vol. 78, no. 6, pp. 1360-1380, 1973.

[34] P. W. G. Morris, "Cleland and King: project management and the systems approach," International Journal of Managing Projects in Business, vol. 5, no. 4, pp. 634-642, 2012.

[35] A. Pouloudi and E. A. Whitley, "Stakeholder identification in inter-organizational systems: gaining insights for drug use management systems," European Journal of Information Systems, vol. 6, no. 1, pp. 1-14, 1997.

[36] S. Olander, "Stakeholder impact analysis in construction project management," Construction Management and Economics, vol. 25, no. 3, pp. 277-287, 2007.

[37] J. T. Karlsen, "Project stakeholder management," Engineering Management Journal, vol. 14, no. 4, pp. 19-24, 2002.

[38] S. Rowlinson and Y. K. F. Cheung, "Stakeholder management through empowerment: modelling project success," Construction Management and Economics, vol. 26, no. 6, pp. 611-623, 2008.
[39] S. Ward and C. Chapman, "Stakeholders and uncertainty management in projects," Construction Management and Economics, vol. 26, no. 6, pp. 563-577, 2008.

[40] Q. Meng, J. Chen, and K. Qian, "The complexity and simulation of revenue sharing negotiation based on construction stakeholders," Complexity, vol. 2018, pp. 1-11, Article ID 5698170, 2018. 